\title{
Late outcomes of off-pump versus on-pump coronary bypass in patients with diabetes: A nationwide study from Taiwan
}

Kuan-Chih Huang, MD, ${ }^{\mathrm{a}}$ I-Hui Wu, MD, ${ }^{\mathrm{b}}$ Nai-Kuan Chou, MD, ${ }^{\mathrm{b}}$ Yen-Yun Yang, ${ }^{\mathrm{c}}$ Lung-Chun Lin, MD, $\mathrm{Hsi}-\mathrm{Yu} \mathrm{Yu}, \mathrm{MD}^{\mathrm{b}}$ and Nai-Hsin Chi, $\mathrm{MD}^{\mathrm{b}}$

\section{ABSTRACT}

Objectives: Although the benefits and risks of on- and off-pump coronary artery bypass have been compared in several clinical trials, large-scale studies regarding long-term outcomes in patients with diabetes are lacking. We compared long-term outcomes after on- and off-pump coronary artery bypass in patients with diabetes.

Methods: We evaluated outcomes in 16,215 patients with diabetes who underwent isolated coronary artery bypass from 2000 to 2011. Clinical data validity was regulated by the single-payer, universal, and nationwide reimbursement systems. Long-term outcomes were compared using propensity score matched analyses.

Results: Off-pump surgery was associated with a greater incidence of repeat revascularization $(P=.0036)$ in the long term. Propensity score matching identified 3796 patients in each group. There were no significant differences between on- and off-pump surgery regarding the long-term risks of mortality (hazard ratio [HR], 0.95; 95\% confidence interval [CI], 0.87-1.02, $P=.1667$ ), stroke (HR, $0.97 ; 95 \% \mathrm{CI}, 0.87-1.09, P=.6074)$, and myocardial infarction (HR, 1.05; 95\% CI, 0.91-1.20, $P=.5207)$. Off-pump surgery offered a survival benefit within 30 days (HR on vs off, 1.52, 95\% CI, 1.24-1.85, $P<.0001)$. In patients with diabetes and end-stage renal disease, on-pump surgery provided a significant long-term survival benefit ( $\mathrm{HR}$ on vs off, 0.68, 95\% CI, 0.51-0.91).

Conclusions: In patients with diabetes undergoing isolated coronary artery bypass, off-pump surgery provided a 30-day benefit in mortality, but both groups had similar long-term survival. In off-pump surgery, repeat revascularization was a concern in the long term. In patients with diabetes and end-stage renal disease, on-pump surgery has long-term survival benefits. (J Thorac Cardiovasc Surg 2019;157:960-9)

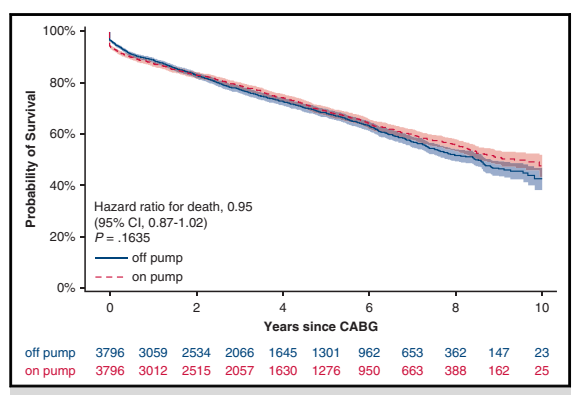

Off-pump and on-pump surgery had equal long-term mortality in patients with diabetes.

\section{Central Message}

In patients with diabetes, off-pump coronary artery bypass offered a survival benefit within 30 days. Off-pump and on-pump surgery had similar long-term survival.

\section{Perspective}

Long-term results of off-pump versus on-pump coronary artery bypass in patients with diabetes, especially in Asian population, are lacking. In patients with diabetes, whether offpump or on-pump coronary artery bypass is to be performed depends not only on 30-days outcomes but also on longer-term outcomes.

See Commentaries on pages 970, 972, and 974.
In patients undergoing coronary artery bypass graft surgery $(\mathrm{CABG})$, diabetes mellitus increases short-term

From the Departments of ${ }^{\mathrm{a}}$ Internal Medicine and ${ }^{\mathrm{b}}$ Surgery, National Taiwan University Hospital and National Taiwan University College of Medicine, Taipei; and ${ }^{\mathrm{c}}$ National Taiwan University, Health Data Research Center, Taipei, Taiwan.

Supported in part by the Ministry of Science and Technology (105-2314-B-002-128MY2).

Received for publication Nov 2, 2017; revisions received July 31, 2018; accepted for publication Aug 1, 2018; available ahead of print Oct 25, 2018.

Address for reprints: Nai-Hsin Chi, MD, Department of Surgery, National Taiwan University Hospital and National Taiwan University College of Medicine, No. 7, Chung Shan S. Rd, Zhongzheng Dist, Taipei City 10002 (E-mail: chinaihsin@ gmail.com).

$0022-5223 / \$ 36.00$

Copyright (c) 2018 by The American Association for Thoracic Surgery

https://doi.org/10.1016/j.jtcvs.2018.08.084 mortality $^{1}$ and morbidity. ${ }^{2,3}$ CABG when compared with percutaneous coronary intervention has superior outcomes in patients with diabetes. ${ }^{4}$ Diabetes itself is an adverse outcome predictor in this specific patient group. Patients with diabetes who underwent CABG had worse survival outcomes than those without diabetes (Figure E1). Morbidities such as stroke, renal failure, and infection are

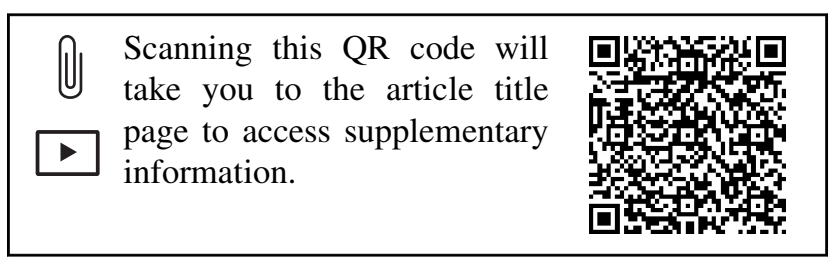




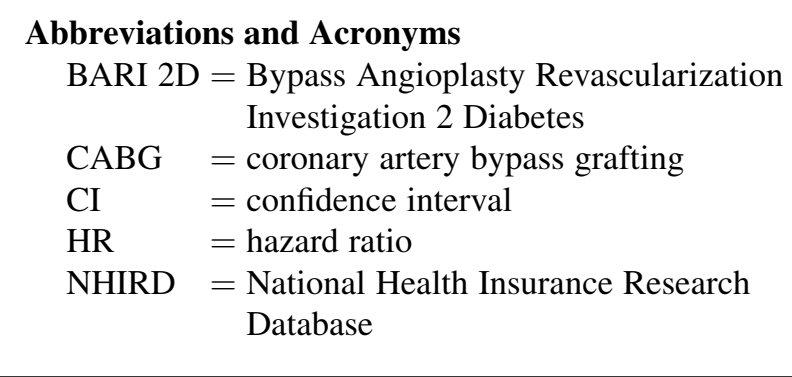

considered to be associated with cardiopulmonary bypass. ${ }^{3,5-10}$ Off-pump CABG has been proven to be beneficial in reducing such postoperative morbidities in patients with diabetes ${ }^{11-13}$; however, there is a controversy regarding the long-term results of off- versus on-pump CABG, ${ }^{9,10,14-}$ ${ }^{19}$ and the long-term all-cause mortality and repeat revascularization rate of off-pump CABG in patients with diabetes remain unclear. ${ }^{11,20}$ We believed that by studying the longterm outcomes of patients with diabetes who underwent CABG, we can provide surgeons with clear insights on the surgical strategy in specific patients with diabetes. The main objective of this study was to compare long-term outcomes after off- and on-pump CABG in patients with diabetes by using data from the National Health Insurance Research Database (NHIRD) in Taiwan.

\section{METHODS \\ Patients}

The study was approved by the Research Ethics Committee of National Taiwan University Hospital (institutional review board approval: $201802001 \mathrm{~W}$ ). All patients undergoing cardiac surgery are prospectively registered in the NHIRD, which records baseline patient characteristics and surgery type (regarding usage of cardiopulmonary bypass, the amount of coronary arteries grafted) as original claim data for obligatory reimbursement under the single-payer National Health Insurance program in Taiwan. As a result, even if a patient is not followed at the same hospital in which the CABG was performed, all of the clinical data at any other hospital would still be registered after each medical service. A total of 41,155 patients who underwent CABG between 2000 and 2011 were identified (Figure 1); we excluded patients younger than 18 years of age $(n=159)$, foreigners $(n=134$; foreigners who went back to their own country after surgery were not followed in the national health system), those who underwent emergency surgery $(\mathrm{n}=1484)$, and those who underwent concomitant valvular surgery $(n=6383)$.

Finally, 32,995 patients who met the inclusion criteria formed the overall study population. Of these, $49.1 \%$ patients $(n=16,215)$ were diagnosed with diabetes mellitus: 4100 patients with diabetes $(25.3 \%)$ underwent offpump CABG, 9341 (57.6\%) underwent on-pump CABG, and 2774 $(17.1 \%)$ underwent on-pump beating-heart CABG. The on-pump beating-heart $\mathrm{CABG}$ group was excluded to compare the effects of cardiac pulmonary bypass under the same situation as in previous studies. ${ }^{10,16}$ There might be some off-pump conversion putting in this category; therefore, to examine the pure off-pump and on-pump differences, patients who underwent on-pump beating-heart CABG were excluded. The perioperative data and incidence rates of mortality and morbidity were also extracted from the NHIRD. The duration of follow-up was calculated from the date of surgery to that of death or the last medical contact.

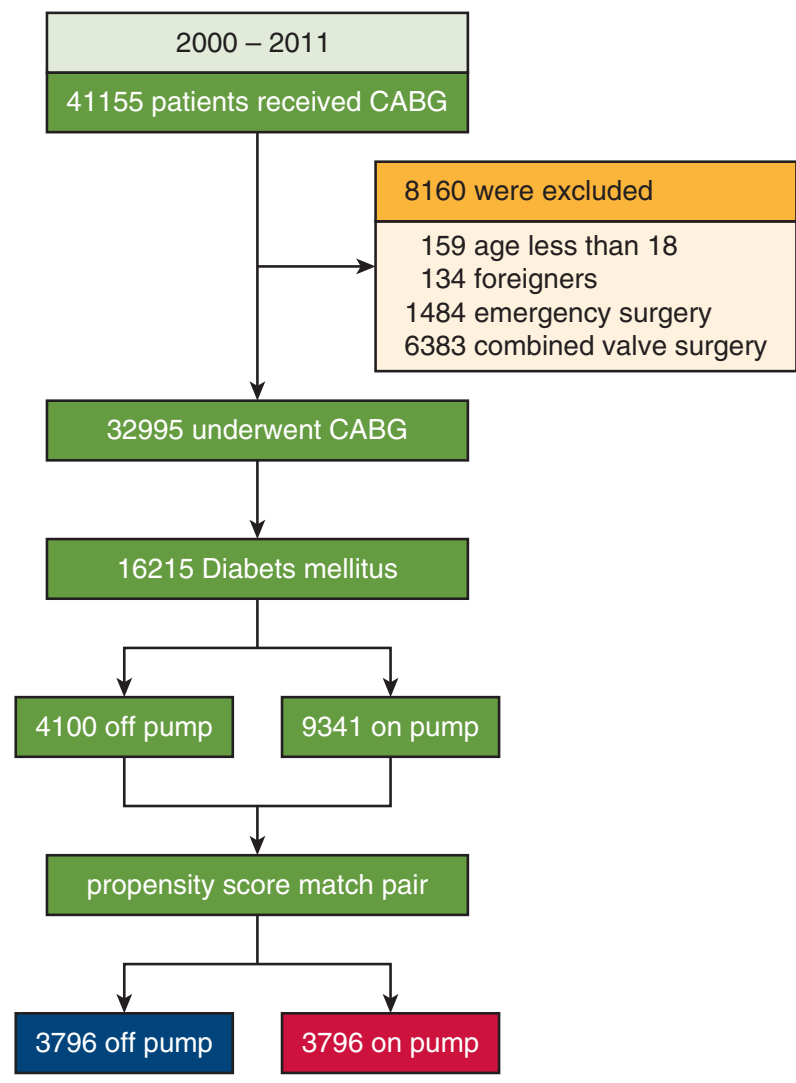

FIGURE 1. Enrollment, grouping, and follow-up of patients. For some of the 8160 patients who were excluded, there was more than one reason for exclusion. In 15,338 patients with diabetes with isolated coronary artery bypass, those who were operated under cardiopulmonary bypass with heart beating were excluded for grouping. $C A B G$, Coronary artery bypass grafting.

Preoperative patient data were obtained relative to age (stratified into 18-64, 65-74, and 75+ years), sex, hypertension, previous stroke, history of myocardial infarction, peripheral vascular disease, chronic obstructive pulmonary disease, pacemaker implantation, atrial fibrillation, cancer, chronic kidney disease, renal-replacement therapy, extent of coronary artery disease, and hospital volume of CABG. Diabetes mellitus treatment details were also extracted and categorized as oral medication control and insulin control. Guidelines recommend that medication such as aspirin, statins, and angiotensin II receptor be reimbursed in Taiwan; thus, we did not evaluate the prescription status in our study.

\section{Study Endpoints}

The primary endpoint of our study was mortality and the principal secondary composite endpoint included death, stroke, myocardial infarction, and repeat revascularization. Cardiovascular disease-related and cerebrovascular disease-related deaths were also documented. Hazard ratios (HRs) of the aforementioned endpoints were analyzed at 30 days and 1 year and followed up to 10 years or death/censoring.

\section{Statistical Analysis}

The basic demographic characteristics of the study subjects are shown as numbers and percentages, and the differences are presented with standardized differences. Standardized difference provides a comparison of the mean or prevalence of a baseline covariate between 2 treatment groups in the propensity score matched sample. The $t$-test and $\chi^{2}$ test were performed to test the mean difference and the proportion between on- and 
TABLE 1. Basic demographic characteristics in study subjects before and after propensity adjustment before CABG

\begin{tabular}{|c|c|c|c|c|c|c|c|c|c|c|}
\hline \multirow[b]{3}{*}{ Characteristic } & \multicolumn{4}{|c|}{ Before PS matching } & \multirow{3}{*}{$\begin{array}{l}\text { Standardized } \\
\text { difference }(\%)\end{array}$} & \multicolumn{4}{|c|}{ After PS matching } & \multirow{3}{*}{$\begin{array}{r}\text { Standardized } \\
\text { difference }(\%)\end{array}$} \\
\hline & \multicolumn{2}{|c|}{$\begin{array}{c}\text { Off-pump } \\
\text { CABG }\end{array}$} & \multicolumn{2}{|c|}{$\begin{array}{l}\text { On-pump } \\
\text { CABG }\end{array}$} & & \multicolumn{2}{|c|}{ Off-pump CABG } & \multicolumn{2}{|c|}{ On-pump CABG } & \\
\hline & $\mathbf{N}$ & $\%$ & $\mathbf{N}$ & $\%$ & & $\mathbf{N}$ & $\%$ & $\mathbf{N}$ & $\%$ & \\
\hline Patients & 4104 & 30.38 & 9405 & 69.62 & & 3796 & 50.00 & 3796 & 50.00 & \\
\hline Age, y (mean/SD) & 65.39 & 10.15 & 65.02 & 9.80 & 3.70 & 65.35 & 10.12 & 65.19 & 10.02 & 1.64 \\
\hline $18-64$ & 1832 & 44.64 & 4279 & 45.50 & 1.72 & 1698 & 44.73 & 1718 & 45.26 & 1.06 \\
\hline $65-74$ & 1455 & 35.45 & 3473 & 36.93 & 3.07 & 1354 & 35.67 & 1360 & 35.83 & 0.33 \\
\hline $75+$ & 817 & 19.91 & 1653 & 17.58 & 5.98 & 744 & 19.60 & 718 & 18.91 & 1.74 \\
\hline Sex, female & 1238 & 30.17 & 2887 & 30.70 & 1.15 & 1137 & 29.95 & 1133 & 29.85 & 0.23 \\
\hline Insulin & 515 & 12.55 & 1468 & 15.61 & 8.81 & 481 & 12.67 & 509 & 13.41 & 2.19 \\
\hline Hypertension & 3422 & 83.38 & 7750 & 82.40 & 2.60 & 3156 & 83.14 & 3177 & 83.69 & 1.49 \\
\hline Previous stroke & 887 & 21.61 & 1969 & 20.94 & 1.66 & 804 & 21.18 & 754 & 19.86 & 3.26 \\
\hline History of myocardial infarction & 1189 & 28.97 & 2664 & 28.33 & 1.43 & 1095 & 28.85 & 1015 & 26.74 & 4.71 \\
\hline Peripheral vascular disease & 295 & 7.19 & 614 & 6.53 & 2.61 & 268 & 7.06 & 261 & 6.88 & 0.72 \\
\hline $\begin{array}{l}\text { Chronic obstructive pulmonary } \\
\text { disease }\end{array}$ & 365 & 8.89 & 810 & 8.61 & 1.00 & 331 & 8.72 & 304 & 8.01 & 2.57 \\
\hline Implanted pacemaker & 78 & 1.90 & 140 & 1.49 & 3.19 & 70 & 1.84 & 52 & 1.37 & 3.77 \\
\hline History of atrial fibrillation & 133 & 3.24 & 320 & 3.40 & 0.90 & 120 & 3.16 & 101 & 2.66 & 2.98 \\
\hline Cancer & 209 & 5.09 & 416 & 4.42 & 3.15 & 187 & 4.93 & 161 & 4.24 & 3.28 \\
\hline Renal-replacement therapy & 25 & 0.61 & 41 & 0.44 & 2.40 & 22 & 0.58 & 21 & 0.55 & 0.35 \\
\hline Chronic kidney disease & 227 & 5.53 & 373 & 3.97 & 7.36 & 205 & 5.40 & 204 & 5.37 & 0.12 \\
\hline Renal function normal & 3852 & 93.86 & 8991 & 95.60 & 7.79 & 3569 & 94.02 & 3571 & 94.07 & 0.22 \\
\hline \multicolumn{11}{|l|}{ Extent of coronary artery disease } \\
\hline One-vessel disease & 377 & 9.19 & 172 & 1.83 & 32.68 & 177 & 4.66 & 145 & 3.82 & 4.18 \\
\hline Two-vessel disease & 786 & 19.15 & 1364 & 14.50 & 12.45 & 684 & 18.02 & 674 & 17.76 & 0.69 \\
\hline Three-vessel disease & 2941 & 71.66 & 7869 & 83.67 & 29.13 & 2935 & 77.32 & 2977 & 78.42 & 2.67 \\
\hline \multicolumn{11}{|l|}{ Hospital volume for CABG } \\
\hline $\operatorname{High}(\geq 200 / y)$ & 2663 & 64.89 & 4106 & 43.66 & 43.62 & 2423 & 63.83 & 2446 & 64.44 & 1.26 \\
\hline middle (100 199/y) & 668 & 16.28 & 2578 & 27.41 & 27.19 & 642 & 16.91 & 592 & 15.60 & 3.57 \\
\hline Low $(\leq 99 / y)$ & 773 & 18.84 & 2721 & 28.93 & 23.85 & 731 & 19.26 & 758 & 19.97 & 1.79 \\
\hline \multicolumn{11}{|l|}{ Year of surgery } \\
\hline 2001 & 61 & 1.49 & 997 & 10.60 & 38.97 & 61 & 1.61 & 56 & 1.48 & 1.07 \\
\hline 2002 & 304 & 7.41 & 961 & 10.22 & 9.93 & 296 & 7.80 & 277 & 7.30 & 1.89 \\
\hline 2003 & 434 & 10.58 & 848 & 9.02 & 5.24 & 405 & 10.67 & 392 & 10.33 & 1.12 \\
\hline 2004 & 487 & 11.87 & 913 & 9.71 & 6.96 & 444 & 11.70 & 425 & 11.20 & 1.57 \\
\hline 2005 & 373 & 9.09 & 861 & 9.15 & 0.23 & 351 & 9.25 & 381 & 10.04 & 2.68 \\
\hline 2006 & 414 & 10.09 & 872 & 9.27 & 2.76 & 379 & 9.98 & 386 & 10.17 & 0.61 \\
\hline 2007 & 381 & 9.28 & 823 & 8.75 & 1.86 & 357 & 9.40 & 351 & 9.25 & 0.54 \\
\hline 2008 & 438 & 10.67 & 838 & 8.91 & 5.93 & 398 & 10.48 & 394 & 10.38 & 0.34 \\
\hline 2009 & 422 & 10.28 & 837 & 8.90 & 4.70 & 382 & 10.06 & 415 & 10.93 & 2.84 \\
\hline 2010 & 419 & 10.21 & 814 & 8.65 & 5.32 & 380 & 10.01 & 392 & 10.33 & 1.05 \\
\hline 2011 & 371 & 9.04 & 641 & 6.82 & 8.24 & 343 & 9.04 & 327 & 8.61 & 1.49 \\
\hline
\end{tabular}

$P S$, Propensity score; $C A B G$, coronary artery bypass grafting; $S D$, standard deviation.

off-pump CABG patients, respectively. Univariate and multivariate Cox proportional hazard models were used to evaluate the relationship between on- and off-pump CABG and survival. When we explored the relative hazards concerning clinical outcomes other than all-cause death, we treated death as a competing risk instead of a censoring event.

We used every variable in Table 1 as a matching variable to generate a propensity score model to adjust for selection bias in the choice of operative approach. Logistic regression was performed with the choice of operative approach —on-pump versus off-pump—as the dependent variable. Age, sex, diabetes mellitus treated with insulin, hypertension, stroke, history of myocardial infarction, peripheral vascular disease, chronic obstructive pulmonary disease, pacemaker implantation, atrial fibrillation, cancer, renal-replacement therapy, chronic kidney disease, normal renal function, extent of coronary artery disease (1-vessel, 2-vessel, and 3- 
vessel), hospital volume of CABG (high: $\geq 200 /$ year, medium: 100-199/ year, low: $\leq 99 /$ year), and operation year were entered into the model. We used 0.2 as a caliber of width and 1:1 greedy matching method (propensity score matching model concordance-statistics $=0.782$ ) (Figure E2). Cox proportional hazard models were used to estimate the HRs within the specific subgroup. Kaplan-Meier curves and log-rank tests were performed to test the difference in survival probability between the on- and off-pump CABG groups. Statistical analyses were performed using SAS 9.4 (SAS Institute, Cary, NC), and $P<.05$ was considered statistically significant.

\section{RESULTS}

\section{Baseline Characteristics}

All of the patients with diabetes who underwent isolated CABG from 2000 to 2011 in Taiwan were included in this final analysis. The median follow-up period was 5.42 years, and the longest time of survival was 15 years.

The baseline characteristics of a total of 13,441 patients with diabetes, before and after propensity score matching, are shown in Table 1. Patients who underwent off-pump CABG were older and had a greater prevalence of impaired renal function. However, the on-pump group had more severe coronary artery disease. Among the on-pump and off-pump groups, $8367 \%$ and $71.66 \%$ of the patients, respectively, had 3-vessel disease in coronary territories (standardized difference $29.3 \%$ ). Majority of the offpump procedures were performed in high-volume centers $(64.89 \%)$. After matching, we analyzed 3796 patients in each group, and both off-pump and on-pump groups shared the same distribution across all variables (Table 1).

\section{Outcomes of CABG in All Patients With Diabetes}

The survival was better in the off-pump group (HR, 1.52, 95\% confidence interval $[\mathrm{CI}], 1.24-1.85, P<.0001$ at 30 days; HR, $1.16,95 \% \mathrm{CI}, 1.01-1.32, P=.0302$ at 1 year) (Table 2). At 1 year, the on-pump group had a greater risk of all-cause mortality and cardiovascular diseaserelated death (HR, 1.50, 95\% CI, 1.17-1.92, $P=.0013$ ); however, this risk was not significant in the long-term follow-up (Table 2). The long-term event-free rate at 10 years (Figure 2, A) did not differ significantly for allcause mortality $(42.90 \%$ off-pump vs $47.91 \%$ on-pump, $P=.1635)$ or death/myocardial infarction/stroke (Figure $2, B)(22.70 \%$ off-pump vs $23.44 \%$ on-pump, $P=.8274)$. In the long-term follow-up, there were no differences in terms of myocardial infarction and stroke rate. The 10 -year event-free rate for myocardial infarction was $75.3 \%$ in the off-pump group and $76.13 \%$ in the on-pump group $(P=.5205)$ (Figure 3, B). The 10-year event-free rate for stroke was $65.23 \%$ in the off-pump group and $64.32 \%$ in the on-pump group $(P=.6077)$ (Figure $3, A)$. Regarding repeat revascularization (Figure 4 ), the long-term eventfree rate was significantly lower in the off-pump group than in the on-pump group (58.24\% vs $65.23 \%, P=.0036)$.

\section{Subgroup Analyses}

Figure 5 shows the adjusted HRs for all-cause mortality and the composite endpoint (death, stroke, myocardial infarction, and repeat revascularization) in on-pump and off-pump CABG across various demographic and clinical comorbidity subgroups.

At 30 days, off-pump surgery showed superior survival outcomes in majority of subgroups: age younger than 75 years, sex, diabetes mellitus treated with insulin, hypertension, and cerebral vascular disease. At 1 year, off-pump surgery showed survival benefit only in patients younger than 75 years of age; both surgical methods had equal survival outcomes in all other subgroups.

In contrast, at the 10-year follow-up, a nonsignificant poorer survival for off-pump CABG was observed in the chronic kidney disease subgroup. There was a significant survival benefit in patients with end-stage renal disease and diabetes who underwent on-pump surgery (HR 0.68, 95\% CI, 0.51-0.91).

\section{DISCUSSION}

The ROOBY (Outcomes Following Myocardial Revascularization: On and Off Cardiopulmonary Bypass) and CORONARY (CABG Off or On Pump Revascularization) studies led to the controversy regarding the selection of off-pump and on-pump bypass revascularization. The rate of repeat revascularization was predominantly emphasized by those who advocated on-pump surgery as a safer procedure. ${ }^{15,16}$ However, the supporters of off-pump surgery focused on perioperative complications, especially in the high-risk population. ${ }^{21}$ Similar issues were considered in the Bypass Angioplasty Revascularization Investigation 2 Diabetes (BARI 2D) study population and the results showed a greater 4-year risk of major cardiovascular events,$^{20}$ which was not demonstrated in our 30-day results after adjustment and propensity score matching. However, the discrepant prevalence of off-pump surgery among registry countries and the different baseline characteristics in BARI 2D were challenged.

To the best of our knowledge, the NHIRD study population is currently the largest nationwide database for CABG in patients with diabetes, with a nearly $100 \%$ national coverage. Moreover, detailed clinical follow-up data, such as cardiac death, stroke, myocardial infarction, and repeat revascularization, which were not available in the BARI 2D population, were clearly documented due to the regulation of National Health Insurance. Taiwan database is allinclusive of patients and events and is essentially a record of every billed/paid medical event. Our study data are also linked to the death profile in the government registration; therefore, all the events including death were accurately analyzed. 
TABLE 2. Hazard ratios $(95 \%$ CI $)$ of different outcomes using off-pump as reference group

\begin{tabular}{|c|c|c|c|c|c|c|c|c|c|c|c|c|}
\hline \multirow[b]{4}{*}{ Outcome } & \multicolumn{8}{|c|}{30 days } & \multirow{2}{*}{\multicolumn{4}{|c|}{$\begin{array}{c}1 \text { year } \\
\text { Event no. }\end{array}$}} \\
\hline & \multicolumn{4}{|c|}{ Event no. } & \multicolumn{3}{|c|}{ Hazard ratio (On:off) } & \multirow[b]{3}{*}{$P$ value } & & & & \\
\hline & \multicolumn{2}{|c|}{ On-pump } & \multicolumn{2}{|c|}{ Off-pump } & \multirow[b]{2}{*}{ HR } & \multicolumn{2}{|c|}{$95 \%$ CI } & & \multicolumn{2}{|c|}{ On-pump } & \multicolumn{2}{|c|}{ Off-pump } \\
\hline & $\mathbf{N}$ & $\%$ & $\mathbf{N}$ & $\%$ & & Low & $\mathbf{U p}$ & & $\mathbf{N}$ & $\%$ & $\mathbf{N}$ & $\%$ \\
\hline Death & 248 & 6.53 & 165 & 4.35 & 1.52 & 1.24 & 1.85 & $<.0001$ & 465 & 12.25 & 406 & 10.70 \\
\hline Cardiovascular-related death & 101 & 2.66 & 58 & 1.53 & 1.78 & 1.29 & 2.46 & .0005 & 156 & 4.11 & 106 & 2.79 \\
\hline Cerebrovascular disease death & 5 & 0.13 & 5 & 0.13 & 1.01 & 0.29 & 3.48 & .9906 & 12 & 0.32 & 18 & 0.47 \\
\hline Myocardial infarction & 8 & 0.21 & 10 & 0.26 & 0.80 & 0.32 & 2.03 & .6411 & 158 & 4.16 & 124 & 3.27 \\
\hline Stroke & 17 & 0.45 & 17 & 0.45 & 1.00 & 0.51 & 1.96 & .9960 & 217 & 5.72 & 209 & 5.51 \\
\hline Repeat revascularization & 0 & 0.00 & 0 & 0.00 & - & & & & 129 & 3.40 & 159 & 4.19 \\
\hline
\end{tabular}

$H R$, Hazard ratio; $C I$, confidence interval

The percentage of off-pump surgery has remained stable since 2002 , accounting for approximately $30 \%$ of all isolated CABG in Taiwan (Figure E3). To avoid the influence of operation time sequence, the operation year was also matched in our study. In Western countries, the prevalence of off-pump CABG is decreasing, being approximately $20 \%$ or less. However, in Eastern countries, off-pump CABG is still a popular surgical method, with a prevalence of $65 \%$ reported in Japan. ${ }^{22}$ The off-pump technique is quite mature in Taiwan (Video 1); in comparison with the age $>75$ years subgroup in the German Off-Pump Coronary Artery Bypass in Elderly Study (GOPAGE), we had similar outcomes in our subgroup analysis. ${ }^{14}$

Our study has several strengths. First, we recruited the largest number of patients with diabetes. Second, all patients received health reimbursements from the government. All procedures, diagnoses, and treatments in the database were virtually followed without loss. Thus, our results reflect real-world data in Asia.

The major finding of the present study is that in patients with diabetes who underwent CABG, off-pump surgery improved all-cause mortality within 30 days, and the survival benefit persisted until 1 year. In the long-term period, there were no differences in all-cause mortality, myocardial infarction, and stroke between the on-pump and off-pump groups. Off-pump surgery provided survival benefits within 1 year probably due to avoidance of cardiopulmonary bypass. Without inflammatory response of cardiopulmonary bypass, the shortterm outcomes in terms of 30-day and 1-year mortality were better for off-pump surgery. However, the survival benefit did not last in the long term probably due to the revascularization quality, which was always a concern in off-pump surgery.

Interestingly, the repeat revascularization rate was greater in off-pump surgery in the long term, which also reflected the persisting concern of revascularization quality. To reduce the influence of confounding factors of hospital experience and differences, we used hospital CABG volume as a propensity matching variable to eliminate influence of center experience. However, the single surgeon experience and number were not allowed to be retrieved from the NHIRD, as per regulation. Although repeat revascularization was not an absolute adverse outcome but probably a benefit for patient survival, in our study, the repeat revascularization events were not scheduled or planned during operation, because these events never occurred within 30 days, and majority of these events occurred 1 year after CABG. However, in our study, the off-pump group had a greater probability of receiving repeat revascularization. Therefore, surgeons should be aware of this tendency when they perform off-pump CABG in patients with diabetes.

For patients with concomitant diabetes mellitus and endstage renal disease, on-pump CABG provided a $32 \%$ reduction in long-term mortality rate (risk ratio $=0.68,95 \% \mathrm{CI}$, 0.51-0.91). Patients with diabetes experienced diffused narrowing of the coronary arteries compared with those without diabetes. Moreover, in patients with renal failure, calcified coronary arteries would be more profound in disease.

Patients with diabetes have a greater risk of enhanced disease progression in coronary artery disease than those without diabetes, and the impact of incomplete revascularization is considered a major concern in off-pump CABG. ${ }^{20}$ However, in our study, even when the off-pump group underwent more repeat revascularization, the survival rate was not reduced in the long term. However, among patients with diabetes who experienced greater short-term mortality and morbidity, ${ }^{2}$ those who had single-vessel disease will require not only the protective benefit ${ }^{23,24}$ of the internal mammary artery whose long-term patency would not be affected by off-pump surgery ${ }^{25}$ but also the short-term benefit of off-pump surgery. ${ }^{26}$

In our study, the NHIRD recorded all events, diagnosis, and treatment based on the final surgical procedure; therefore, it was difficult to know about the off-pump to onpump conversion. To eliminate the influence of conversion, we selected only cases of off-pump surgery without any usage of cardiopulmonary bypass circuit in the payment system and on-pump surgery without any usage of off-pump equipment such as stabilizers. Indeed, we cannot completely eliminate the influence of conversion; therefore, 
TABLE 2. Continued

\begin{tabular}{|c|c|c|c|c|c|c|c|c|c|c|c|}
\hline \multirow{2}{*}{\multicolumn{3}{|c|}{$\begin{array}{c}1 \text { year } \\
\text { Hazard ratio (On:off) }\end{array}$}} & \multirow[b]{4}{*}{$P$ value } & \multicolumn{8}{|c|}{10 years } \\
\hline & & & & \multicolumn{7}{|c|}{$\begin{array}{l}\text { 10 years } \\
\text { Hazard ratio (On:off) }\end{array}$} & \multirow[b]{3}{*}{$P$ value } \\
\hline \multirow[b]{2}{*}{ HR } & \multicolumn{2}{|c|}{$95 \%$ CI } & & \multicolumn{2}{|c|}{ On-pump } & \multicolumn{2}{|c|}{ Off-pump } & \multirow[b]{2}{*}{ HR } & \multicolumn{2}{|c|}{$95 \%$ CI } & \\
\hline & Low & $\mathbf{U p}$ & & $\mathbf{N}$ & $\%$ & $\mathbf{N}$ & $\%$ & & Low & Up & \\
\hline 1.16 & 1.01 & 1.32 & .0302 & 1142 & 30.08 & 1214 & 31.98 & 0.95 & 0.87 & 1.02 & .1667 \\
\hline 1.50 & 1.17 & 1.92 & .0013 & 219 & 5.77 & 166 & 4.37 & 1.14 & 0.89 & 1.44 & .0946 \\
\hline 0.68 & 0.33 & 1.40 & .2931 & 23 & 0.61 & 32 & 0.84 & 0.73 & 0.43 & 1.24 & .2424 \\
\hline 1.18 & 0.93 & 1.65 & .0713 & 417 & 10.99 & 403 & 10.62 & 1.04 & 0.91 & 1.20 & .5332 \\
\hline 1.04 & 0.86 & 1.26 & .0668 & 612 & 16.12 & 634 & 16.70 & 0.97 & 0.87 & 1.08 & .5586 \\
\hline 0.82 & 0.64 & 1.02 & .0648 & 526 & 13.86 & 617 & 16.25 & 0.84 & 0.75 & 0.95 & .0036 \\
\hline
\end{tabular}

Survival

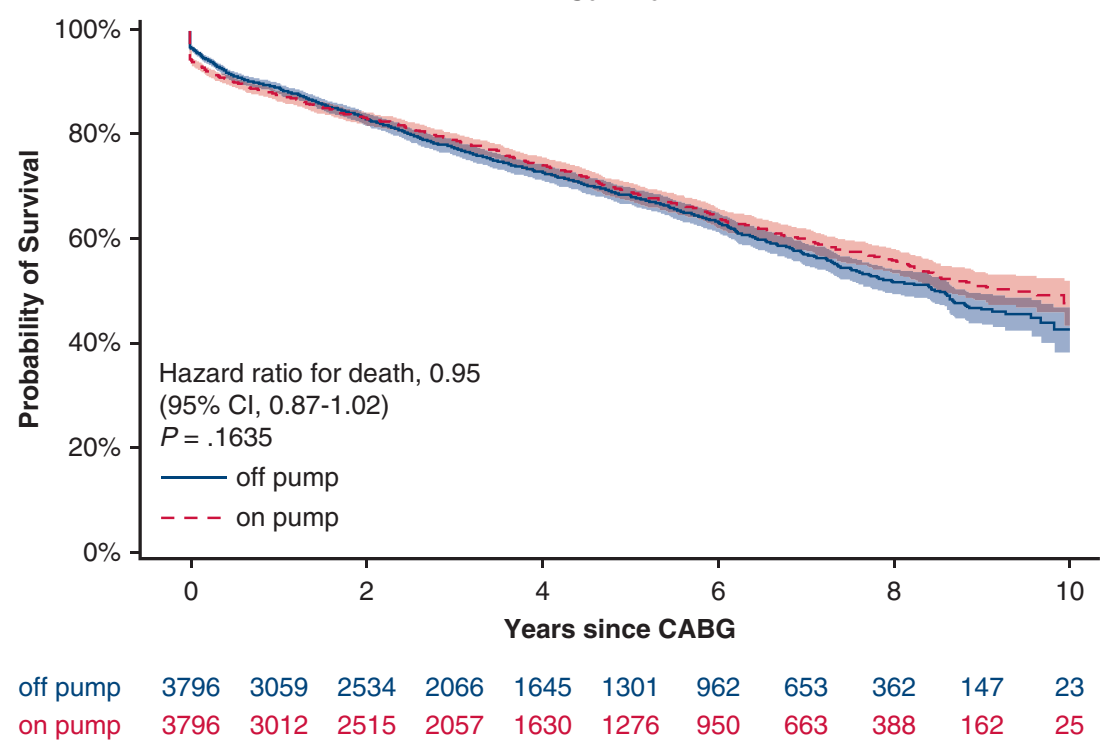

A

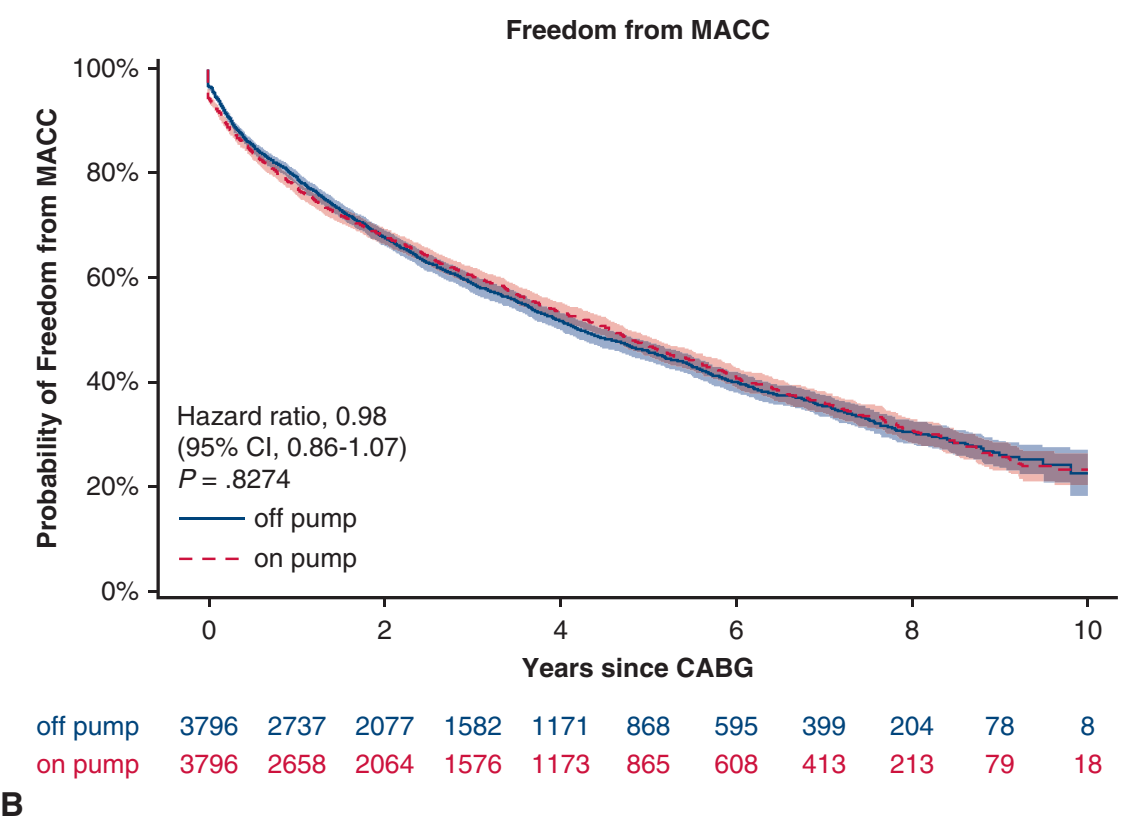

FIGURE 2. Kaplan-Meier curves of patients with diabetes after CABG. A, All-cause mortality survival curve of off-pump and on-pump groups. B, MACC (death, myocardial infarction, and stroke). $C A B G$, Coronary artery bypass grafting; $C I$, confidence interval; $M A C C$, major cardiovascular and cerebral events. 


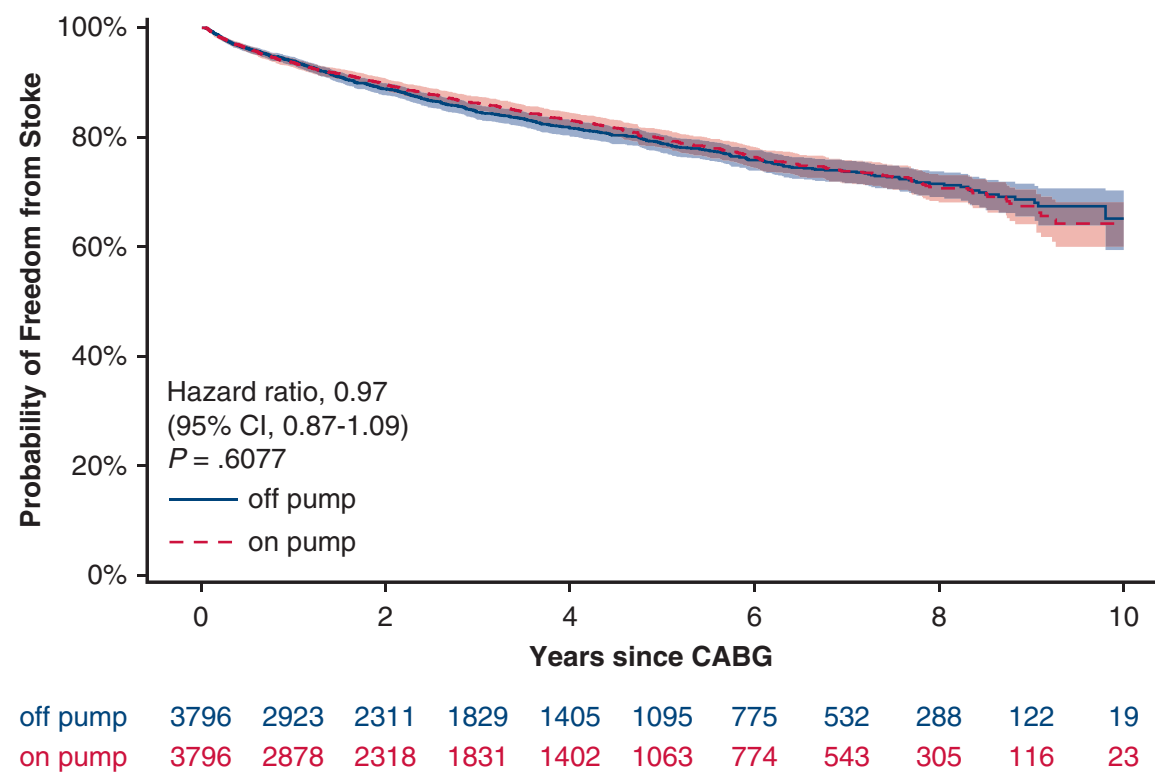

A

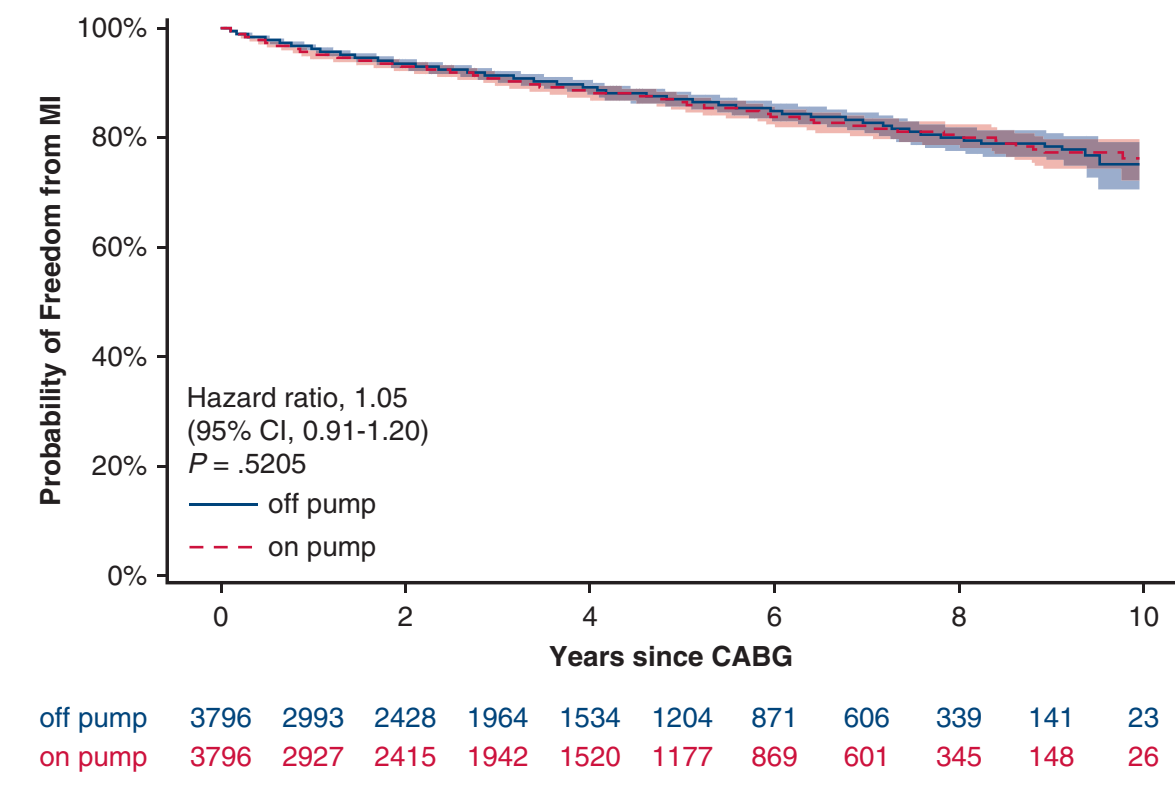

FIGURE 3. Freedom from myocardial infarction and stroke after CABG. A, Freedom from stroke. B, Freedom from myocardial infarction. $C A B G$, Coronary artery bypass grafting; $C I$, confidence interval; $M I$, myocardial infarction.

the outcomes of off-pump surgery may have been overestimated.

The status of chronic kidney disease has been reported to have a strong influence on long-term outcomes after CABG in patients with diabetes, ${ }^{27}$ and the benefit of on-pump CABG was significant in the end-stage renal disease subgroup in our study. On-pump CABG is known to have a greater number of bypasses ${ }^{15,28}$ and superior graft patency, ${ }^{29-31}$ and its renaissance was accompanied by many criticisms of off-pump CABG such as fewer distal anastomoses on inferior and lateral aspects, incomplete revascularization, and poor vein graft patency. However, in the era of aggressive percutaneous coronary intervention and new-generation medications that ameliorate disease progression in patients with diabetes to some degree, the shortcoming of off-pump CABG might be overcome. Moreover, for patients with extremely high atherosclerosis burdens due to the lack of effective medication, the benefit of 


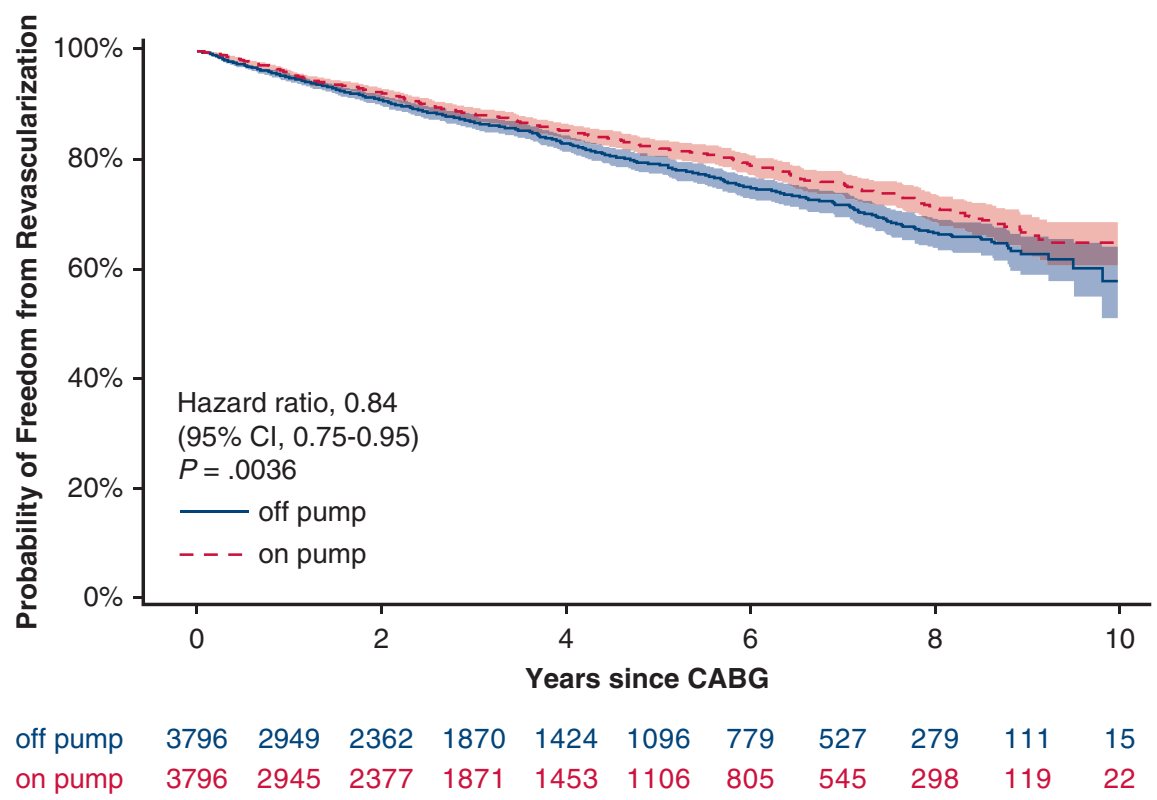

FIGURE 4. Freedom from repeat revascularization. $C I$, Confidence interval; $C A B G$, coronary artery bypass grafting.

on-pump CABG remains evident; the patients with diabetes mellitus and concomitant end-stage renal disease in our study support this notion.

\section{Study Limitations}

Because the study analysis was retrospective and only clinical events and services regulated by reimbursements were recorded, factors such as effectively controlled diabetes mellitus; $\mathrm{HbAlc}$; the completeness of revascularization; left ventricular ejection fraction or patients' functional capacity; choices of conduits (percentage of bilateral internal mammary arteries or total arterial grafting); and surgeon experience were not evaluated. The single surgeon experience cannot be retrieved from the NHIRD;

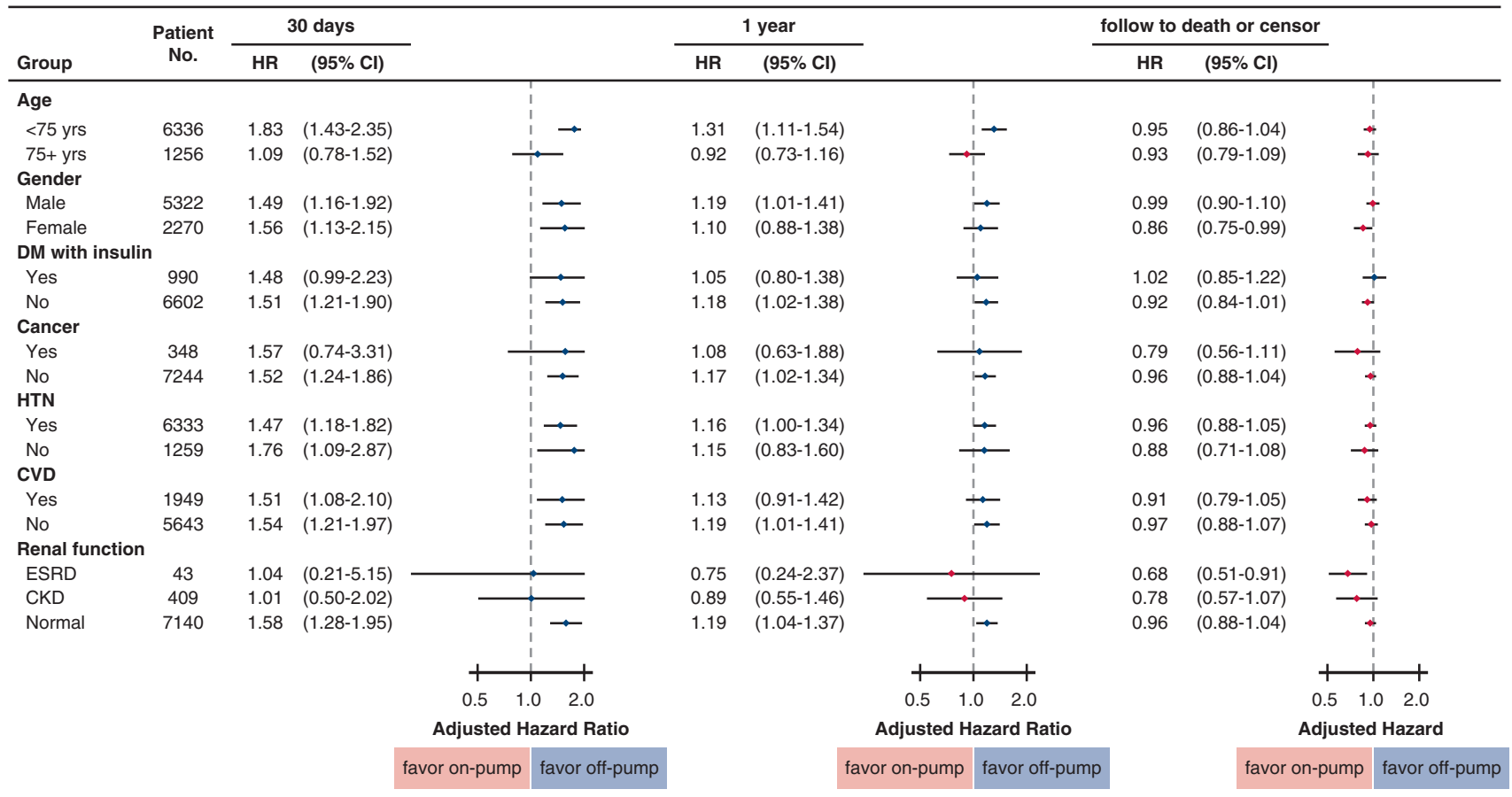

FIGURE 5. Subgroup analyses. $H R$, Hazard ratio; $C I$, confidence interval; $H T N$, hypertension; $C V D$, cardiovascular disease; $E S R D$, end-stage renal disease; $C K D$, chronic kidney disease. 


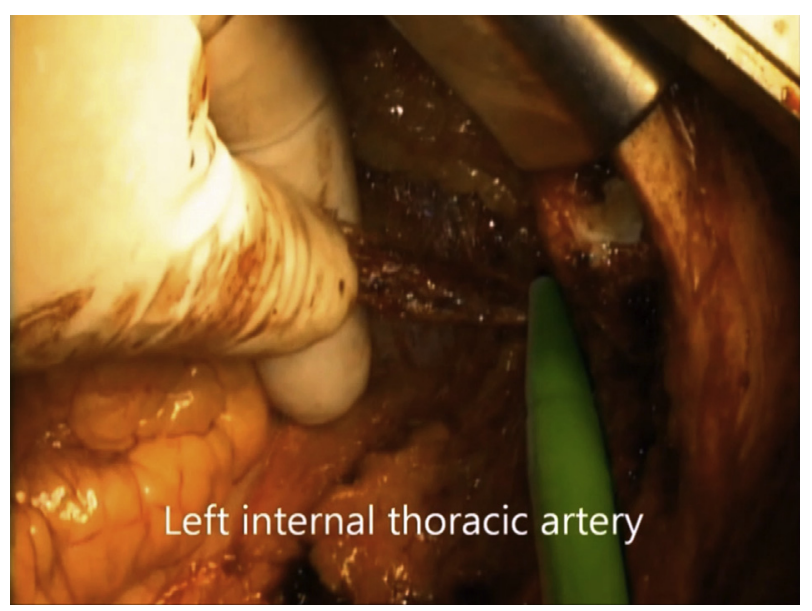

VIDEO 1. Total arterial graft bypass surgery. We describe the total arterial graft coronary artery bypass in National Taiwan University Hospital. The patient was a 64-year-old man with diabetes who had moderate mitral regurgitation and left ventricular ejection fraction $45 \%$. Total arterial graft using T-shape graft, right internal thoracic artery as a free graft attached to the side arm of left internal thoracic artery. The left internal thoracic artery was anastomosed to the left anterior descending artery, and right internal thoracic artery was used to bypass the obtuse marginal branch and posterior descending artery. Video available at: https://www.jtcvs.org/article/S00225223(18)32478-4/fulltext.

therefore, we studied hospital CABG volume and entered this variable into propensity score matching to eliminate the influence of surgeon experience. The decision to perform off- versus on-pump CABG was dependent on the patients' clinical characteristics and surgeons' preferences. Although we attempted to reduce selection bias using statistical methods such as propensity score matching, unmeasured confounders or detection bias may have affected our results.

\section{CONCLUSIONS}

In patients with diabetes, off-pump CABG offered a survival benefit within 30 days. There was no significant difference in myocardial infarction, stroke, and repeat revascularization between the on-pump and off-pump groups during long-term follow-up. However, the offpump group experienced more repeat revascularization in the long term. For patients with concomitant diabetes mellitus and end-stage renal disease, on-pump CABG provided a significant survival benefit.

\section{Conflict of Interest Statement}

Authors have nothing to disclose with regard to commercial support.

The authors thank the staff at the Seventh Core Laboratory, Department of Medical Research, National Taiwan University Hospital, for their technical support. The authors acknowledge the statistical assistance provided by the Taiwan Clinical Trial
Statistical Center, Training Center, and Pharmacogenomics Laboratory. We would especially like to thank Yi-Jia Liou for figure preparation.

\section{References}

1. Nalysnyk L, Fahrbach K, Reynolds MW, Zhao SZ, Ross S. Adverse events in coronary artery bypass graft $(\mathrm{CABG})$ trials: a systematic review and analysis. Heart. 2003;89:767-72.

2. Carson JL, Scholz PM, Chen AY, Peterson ED, Gold J, Schneider SH. Diabetes mellitus increases short-term mortality and morbidity in patients undergoing coronary artery bypass graft surgery. J Am Coll Cardiol. 2002;40: 418-23.

3. Hertzberg D, Sartipy U, Holzmann MJ. Type 1 and type 2 diabetes mellitus and risk of acute kidney injury after coronary artery bypass grafting. Am Heart J. 2015; 170:895-902.

4. Hammoud T, Tanguay JF, Bourassa MG. Management of coronary artery disease: therapeutic options in patients with diabetes. JAm Coll Cardiol. 2000;36:355-65.

5. Pintar T, Collard CD. The systemic inflammatory response to cardiopulmonary bypass. Anesthesiol Clin North Am. 2003;21:453-64.

6. Stroobant N, Van Nooten G, Van Belleghem Y, Vingerhoets G. Relation between neurocognitive impairment, embolic load, and cerebrovascular reactivity following on- and off-pump coronary artery bypass grafting. Chest. 2005;127: 1967-76.

7. Wynne R, Botti M. Postoperative pulmonary dysfunction in adults after cardiac surgery with cardiopulmonary bypass: clinical significance and implications for practice. Am J Crit Care. 2004;13:384-93.

8. Benedetto U, Altman DG, Gerry S, Gray A, Lees B, Flather M, et al. Offpump versus on-pump coronary artery bypass grafting: insights from the Arterial Revascularization Trial. J Thorac Cardiovasc Surg. 2018;155: 1545-53.e7.

9. Filardo G, Hamman BL, da Graca B, Sass DM, Machala NJ, Ismail S, et al. Efficacy and effectiveness of on- versus off-pump coronary artery bypass grafting: a meta-analysis of mortality and survival. J Thorac Cardiovasc Surg. 2018;155: 172-9.e175.

10. A Randomized Trial of Therapies for Type 2 Diabetes and Coronary Artery Disease. N Engl J Med. 2009;360:2503-15.

11. Magee MJ, Dewey TM, Acuff T, Edgerton JR, Hebeler JF, Prince SL, et al. Influence of diabetes on mortality and morbidity: off-pump coronary artery bypass grafting versus coronary artery bypass grafting with cardiopulmonary bypass. Ann Thorac Surg. 2001;72:776-80; discussion 780-1.

12. Renner A, Zittermann A, Aboud A, Pühler T, Hakim-Meibodi K, Quester W, et al. Coronary revascularization in diabetic patients: off-pump versus onpump surgery. Ann Thorac Surg. 2013;96:528-34.

13. Srinivasan AK, Grayson AD, Fabri BM. On-pump versus off-pump coronary artery bypass grafting in diabetic patients: a propensity score analysis. Ann Thorac Surg. 2004;78:1604-9.

14. Diegeler A, Börgermann J, Kappert U, Breuer M, Böning A, Ursulescu A, et al. Off-pump versus on-pump coronary-artery bypass grafting in elderly patients. $N$ Engl J Med. 2013;368:1189-98.

15. Kim JB, Yun SC, Lim JW, Hwang SK, Jung SH, Song H, et al. Long-term survival following coronary artery bypass grafting: off-pump versus on-pump strategies. J Am Coll Cardiol. 2014;63:2280-8.

16. Shroyer AL, Grover FL, Hattler B, Collins JF, McDonald GO, Kozora E, et al. On-pump versus off-pump coronary-artery bypass surgery. $N$ Engl J Med. 2009;361:1827-37.

17. Shroyer AL, Hattler B, Wagner TH, Baltz JH, Collins JF, Carr BM, et al. Comparing off-pump and on-pump clinical outcomes and costs for diabetic cardiac surgery patients. Ann Thorac Surg. 2014;98:38-44; discussion 44-5.

18. Takagi H, Yamamoto H, Iwata K, Goto S-N, Umemoto T. Ask not which can impair early morbidity—ask which can improve late survival: a meta-analysis of randomized trials of off-pump versus on-pump coronary artery bypass. Int $J$ Cardiol. 2012;158:435-8.

19. Halkos ME, Anderson A, Binongo JNG, Stringer A, Lasanajak Y, Thourani VH, et al. Operative strategies to reduce cerebral embolic events during on- and offpump coronary artery bypass surgery: a stratified, prospective randomized trial. $J$ Thorac Cardiovasc Surg. 2017;154:1278-85.e1271.

20. Singh A, Schaff HV, Mori Brooks M, Hlatky MA, Wisniewski SR, Frye RL, et al. On-pump versus off-pump coronary artery bypass graft surgery among patients with type 2 diabetes in the Bypass Angioplasty Revascularization Investigation 2 Diabetes trial. Eur J Cardiothorac Surg. 2016;49:406-16. 
21. Ueki C, Miyata H, Motomura N, Sakaguchi G, Akimoto T, Takamoto S. Offpump versus on-pump coronary artery bypass grafting in patients with left ventricular dysfunction. J Thorac Cardiovasc Surg. 2016;151:1092-8.

22. Japanese Associate for Coronary Artery Surgery (JACAS). Coronary artery surgery results 2013, in Japan. Ann Thorac Cardiovasc Surg. 2014;20: $332-4$.

23. Dimitrova KR, Hoffman DM, Geller CM, Dincheva G, Ko W, Tranbaugh RF. Arterial grafts protect the native coronary vessels from atherosclerotic disease progression. Ann Thorac Surg. 2012;94:475-81.

24. Endo M, Tomizawa Y, Nishida H. Bilateral versus unilateral internal mammary revascularization in patients with diabetes. Circulation. 2003;108: $1343-9$.

25. Zhang B, Zhou J, Li H, Liu Z, Chen A, Zhao Q. Comparison of graft patency between off-pump and on-pump coronary artery bypass grafting: an updated metaanalysis. Ann Thorac Surg. 2014;97:1335-41.

26. Lamy A, Devereaux PJ, Prabhakaran D, Taggart DP, Hu S, Paolasso E, et al. Offpump or on-pump coronary-artery bypass grafting at 30 days. $N$ Engl J Med. 2012;366:1489-97.

27. Ohira S, Doi K, Numata S, Yamazaki S, Kawajiri H, Yaku H. Impact of chronic kidney disease on long-term outcome of coronary artery bypass grafting in patients with diabetes mellitus. Circ J. 2016;80:110-7.
28. Bakaeen FG, Chu D, Kelly RF, Ward HB, Jessen ME, Chen GJ, et al. Performing coronary artery bypass grafting off-pump may compromise longterm survival in a veteran population. Ann Thorac Surg. 2013;95:1952-8; discussion 1959-60.

29. Angelini GD, Culliford L, Smith DK, Hamilton MC, Murphy GJ, Ascione R, et al. Effects of on- and off-pump coronary artery surgery on graft patency, survival, and health-related quality of life: long-term follow-up of 2 randomized controlled trials. J Thorac Cardiovasc Surg. 2009; $137: 295-303$

30. Khan NE, De Souza A, Mister R, Flather M, Clague J, Davies S, et al. A randomized comparison of off-pump and on-pump multivessel coronary-artery bypass surgery. N Engl J Med. 2004;350:21-8.

31. Widimsky P, Straka Z, Stros P, Jirasek K, Dvorak J, Votava J, et al. One-year coronary bypass graft patency: a randomized comparison between off-pump and onpump surgery angiographic results of the PRAGUE-4 trial. Circulation. 2004; 110:3418-23.

Key Words: coronary artery bypass grafting, diabetes mellitus, on-pump, off-pump

Readers who found these articles interesting may also like to read the following papers found in recent and future issues of our sister publications, Seminars in Thoracic and Cardiovascular Surgery and Operative Techniques in Thoracic and Cardiovascular Surgery!

\section{Adult: Coronary}

ORIGINAL SUBMISSION: Frozen Apex Repair of a Dilated Cardiomyopathy. Masashi Komeda. Semin Thoracic Surg 2018: Volume 30, Issue 4.

Editorial Commentary: The Frozen Apex: A Useful Addition to the Surgeons Armamentarium? James Kirklin. Semin Thoracic Surg 2018: Volume 30, Issue 4.

ORIGINAL SUBMISSION: Remote Ischemic Preconditioning in High Risk Cardiovascular Surgery Patients: a RandomizedControlled Trial. Nicole S. Coverdale. Semin Thoracic Surg 2018: 26-33.

Editorial Commentary: Remote Ischemic Preconditioning: a Complex Question with an Even More Complex Answer. Sarah A. Schubert. Semin Thoracic Surg 2018: 34-35. 


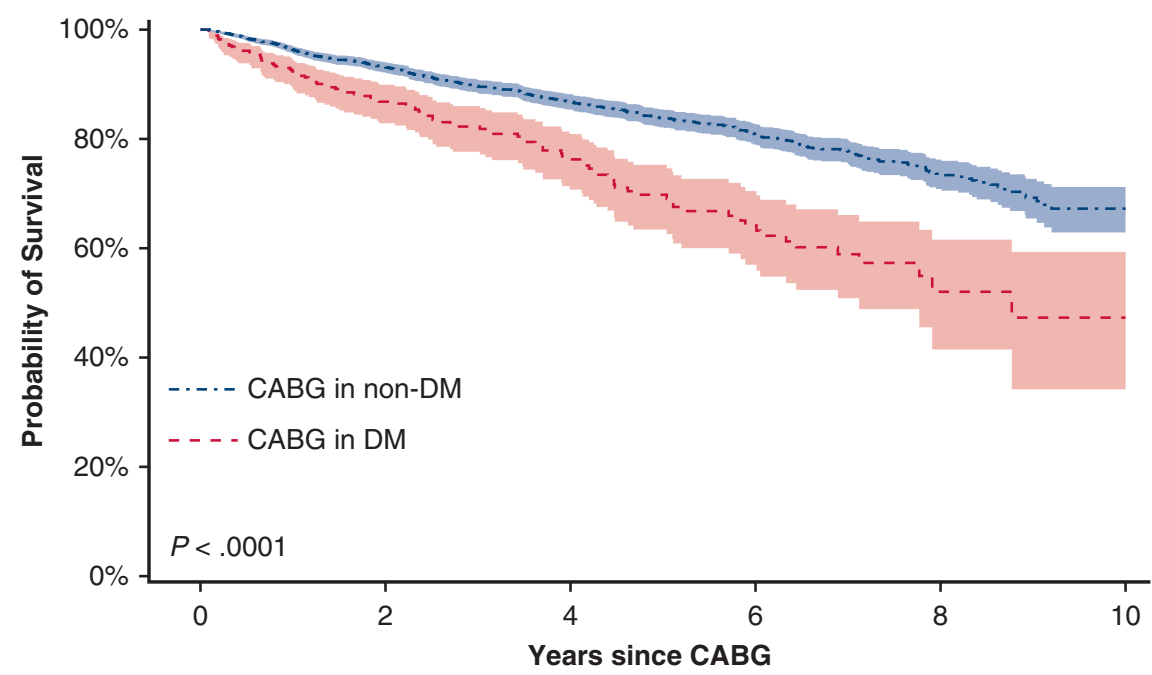

FIGURE E1. All-cause mortality of DM and non-DM after CABG. $C A B G$, Coronary artery bypass grafting; $D M$, diabetes mellitus; non-DM, no diabetes mellitus.

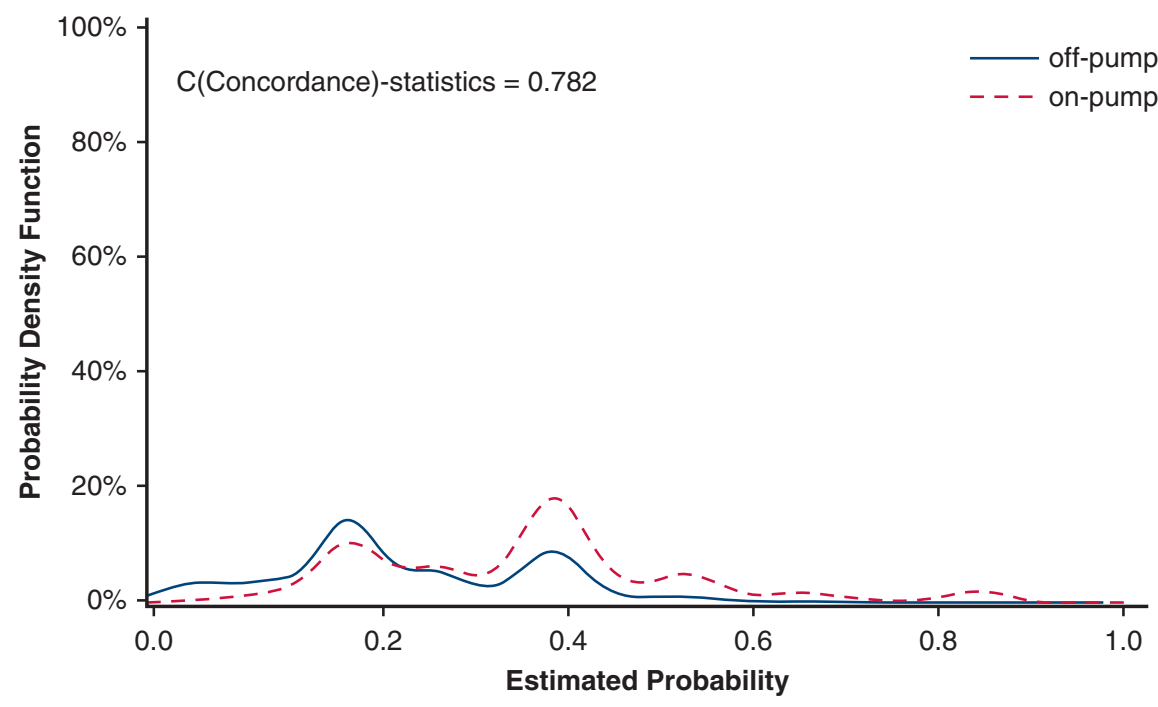

FIGURE E2. PS matching model. PS, Propensity score. 


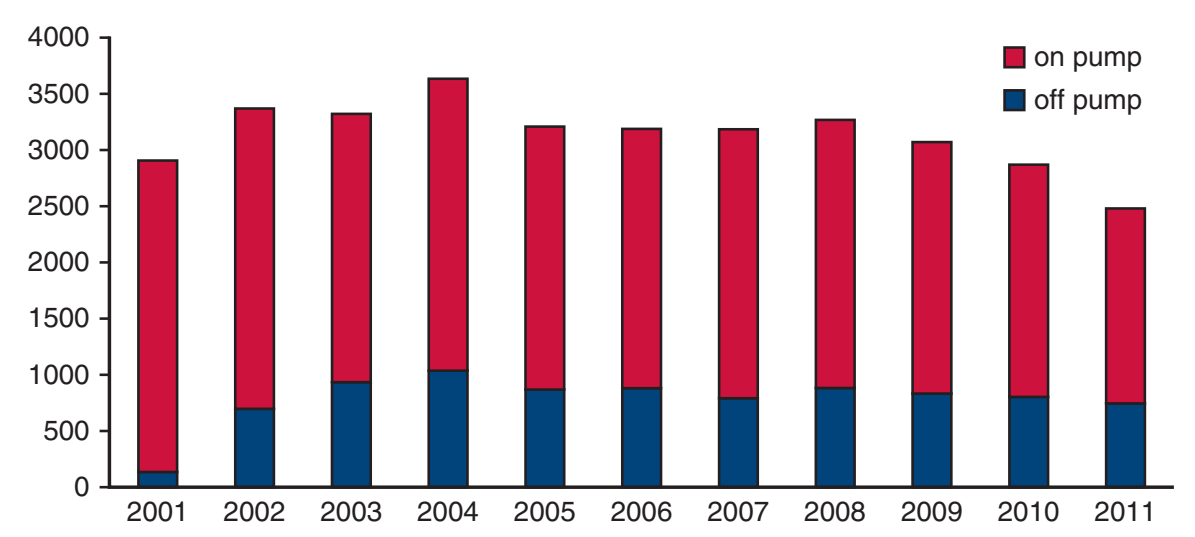

FIGURE E3. Trend of CABG in Taiwan. $C A B G$, Coronary artery bypass grafting. 